\title{
A new locus for Seckel syndrome on chromosome 18p11.31-q11.2
}

\author{
Anders D Børglum ${ }^{*, 1}$, Thomas Balslev ${ }^{2}$, Annette Haagerup ${ }^{1}$, Niels Birkebæk ${ }^{2}$, \\ Helle Binderup ${ }^{1}$, Torben A Kruse ${ }^{3}$ and Jens Michael Hertz ${ }^{4}$
}

${ }^{1}$ Institute of Human Genetics, University of Aarhus, Denmark; ${ }^{2}$ Department of Paediatrics, Aarhus University Hospital, Denmark; ${ }^{3}$ Department of Clinical Biochemistry and Genetics, KKA, Odense University Hospital, Denmark; ${ }^{4}$ Department of Clinical Genetics, Aarhus University Hospital, Denmark

Seckel syndrome (MIM 210600) is a rare autosomal recessive disorder with a heterogeneous appearance. Key features are growth retardation, microcephaly with mental retardation, and a characteristic 'bird-headed' facial appearance. We have performed a genome-wide linkage scan in a consanguineous family of Iraqi descent. By homozygosity mapping a new locus for the syndrome was assigned to a $\sim 30 \mathrm{cM}$ interval between markers D18S78 and D18S866 with a maximum multipoint lod score of 3.1, corresponding to a trans-centromeric region on chromosome 18p11.31-q11.2. This second locus for Seckel syndrome demonstrates genetic heterogeneity and brings us a step further towards molecular genetic delineation of this heterogeneous condition. European Journal of Human Genetics (2001) 9, 753-757.

Keywords: Seckel syndrome; homozygosity mapping; genome scan; linkage analysis

\section{Introduction}

Seckel syndrome (MIM 210600, http://www.ncbi.nlm.nih. gov/Omim) is a rare form of primordial dwarfism with an autosomal recessive inheritance. Besides proportionate intrauterine and postnatal growth retardation the syndrome is characterised by severe microcephaly, a 'bird-headed' profile with receding forehead and chin, prominent and beaked nose, and mental retardation. ${ }^{1}$ Because of the distinct facial characteristics Virchow originally named the condition 'birdheaded' dwarfism. The syndrome appears very heterogeneous, and in a review of 60 reported cases of Seckel syndrome only 17 cases were found to agree with Seckel's case $1 .^{2}$ Recently, a Seckel syndrome locus was mapped to chromosome 3q22.1-q24 by homozygosity mapping of two consanguineous families from the same village in Pakistan. ${ }^{3}$ We report on a genome-wide linkage scan in a consangui-

${ }^{*}$ Correspondence: Anders D Børglum, MD, PhD, Institute of Human Genetics, The Bartholin Building, University of Aarhus, DK-8000 Aarhus C, Denmark. Tel: +45 8942 1672; Fax: +45 8612 3173;

E-mail: anders@humgen.au.dk

Received 8 February 2001; revised 28 May 2001; accepted 27 June 2001 neous family from Iraq with four siblings fulfilling the generally accepted criteria for Seckel syndrome.

\section{Subjects and methods}

Subjects

The parents were first cousins and had four affected children and a younger healthy girl (Figure 1). A summary of the clinical findings observed among the four affected children is presented in Table 1 . The pregnancies and deliveries were uneventful and all were born at term. The birth-weights were between 1.0 and $1.5 \mathrm{~kg}$. At 2 years of age the children walked independently. They had words at 2 years old and after a period of exposure to Danish language they became bilingual. The children were alert and co-operative but a mild global developmental delay was obvious on psychometric testing including subtests from the Wechsler Intelligence Scale for Children, Bender Visual-Motor Gestalt Test and others. The children had a good ability to concentrate on a specific task and a strong will to perform well while specific weaknesses were identified in areas requiring abstract performance like mathematics. All affected children had proportionate short stature with extremely slender extremi- 
ties. The affected siblings were microcephalic with a narrow, not receding, forehead and a prominent nose. The craniums were remarkably small with extreme short anterior cranial base and maxillary length. ${ }^{4}$ MRI of the brain showed mild hypoplasia of the cerebellum in the three oldest siblings, and was not performed in the youngest girl. Examination of the eyes was normal. A cardiac murmur was present in all, but on echocardiography no structural heart defects were observed. The boys had mild hypospadias. In the older boy renal ultrasonic examination revealed ectopic kidneys at the pelvic rim while his siblings showed no structural renal abnormalities. The three oldest children had entered a normal development of secondary sexual characteristics at puberty. Swelling over the proximal part of the middle phalanges in the second, third, and fourth fingers was seen (Figure 2). Clinodactyly of the fifth finger was obvious. On radiological

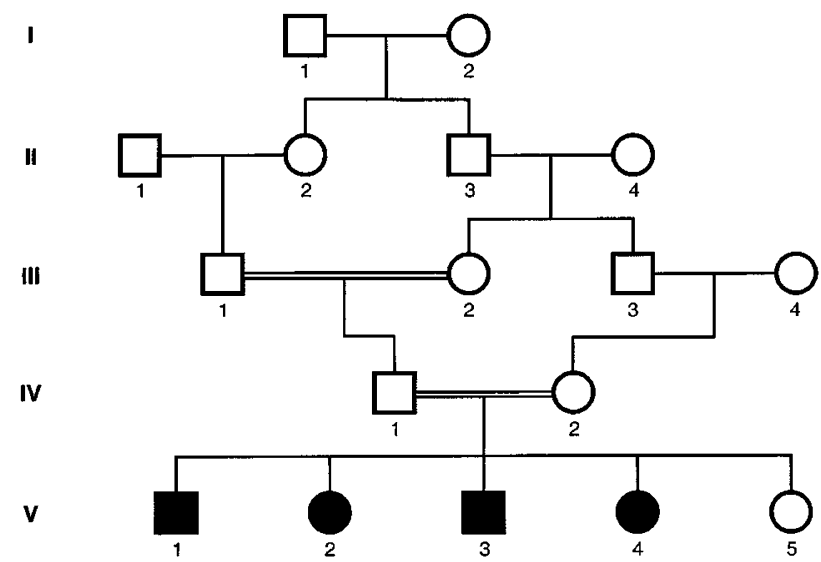

Figure 1 Pedigree of the consanguineous family investigated. DNA was available only from individuals in generation IV and V. studies, absence of the epiphyseal ossification centres of the distal and middle phalangeal bone of the fifth finger was noted. When the older boy was between 16 and 18 years old a synostosis of the distal interphalangeal joint of the fifth finger developed (Figure 3). All affected siblings had one or more small café au lait spots on the skin. Complete blood counts were normal and endocrine studies showed normal growth hormone axis and pituitary-thyroid axis function. Chromosome analysis of the oldest boy was normal with no evidence of increased chromosome breakage.

\section{Genotyping and linkage analysis}

A genome-wide linkage scan was performed using a set of 424 highly informative microsatellite markers from all autosomes with an average spacing of less than $8 \mathrm{cM}$. The markers were selected from the Marshfield genetic map 5 (http://research. marshfieldclinic.org/genetics/MapMarkers/maps/IndexMapFrames.htm). Multiplex PCR was carried out under optimised conditions with an average of 3.5 primer pairs per reaction. PCR products were analysed in 45 multiplex panels, each with products of $4-14$ primer pairs, using an ABI 310 Genetic Analyzer and the ABI Genescan Analysis software (PE Applied Biosystems, Foster City, CA, USA). Two-point and multipoint linkage analyses were performed using the MLINK program of the LINKAGE package version $5.1^{6}$ and the MAPMAKER/ HOMOZ program, ${ }^{7}$ respectively.

\section{Results}

A maximal multipoint lod score of 3.1 was obtained to markers proximal on chromosome 18 . In order to refine the position additional 14 markers from this region were selected from the Marshfield map. A final 30-point MAPMAKER/ HOMOZ analysis localised the Seckel syndrome locus

Table 1 Clinical findings among the four affected children

\begin{tabular}{|c|c|c|c|c|}
\hline & Boy 17 years & Girl 14.5 years & Boy 12.7 years & Girl 10.7 years \\
\hline Low birth weight & + & + & + & + \\
\hline Height, cm (SD) & $146.5(-4.5)$ & $128.9(-5.5)$ & $130.2(-3.5)$ & $107.4(-5.5)$ \\
\hline Weight, kg (SD) & $24.6(-6.5)$ & $20.1(-6.5)$ & $16.9(-5.0)$ & $11.0(-6.5)$ \\
\hline Head circumference, cm (SD) & $45.0(-4.7)$ & $43.5(-5.0)$ & $43.7(-5.0)$ & $43.0(-5.0)$ \\
\hline Narrow forehead and protruding nose & + & + & + & + \\
\hline $\begin{array}{l}\text { Short anterior cranial base and } \\
\text { maxillary length }\end{array}$ & + & + & + & + \\
\hline Global developmental delay (mild) & + & + & + & + \\
\hline High pitched speech & + & + & + & + \\
\hline Cerebellar hyperplasia (MRI) & + & + & + & not available \\
\hline Cardiac murmur & + & + & + & + \\
\hline Hypospadias & + & not applicable & + & not applicable \\
\hline Ectopic kidney at pelvic rim & + & - & - & - \\
\hline Café au lait spots & + & + & + & + \\
\hline Extremely slender extremities & + & + & + & + \\
\hline Clinodactyly of fifth finger & + & + & + & + \\
\hline Swelling over the middle phalanges & + & + & + & + \\
\hline $\begin{array}{l}\text { Absent ossification-centres of distal } \\
\text { and middle epiphyses in fifth finger }\end{array}$ & + & + & + & + \\
\hline
\end{tabular}




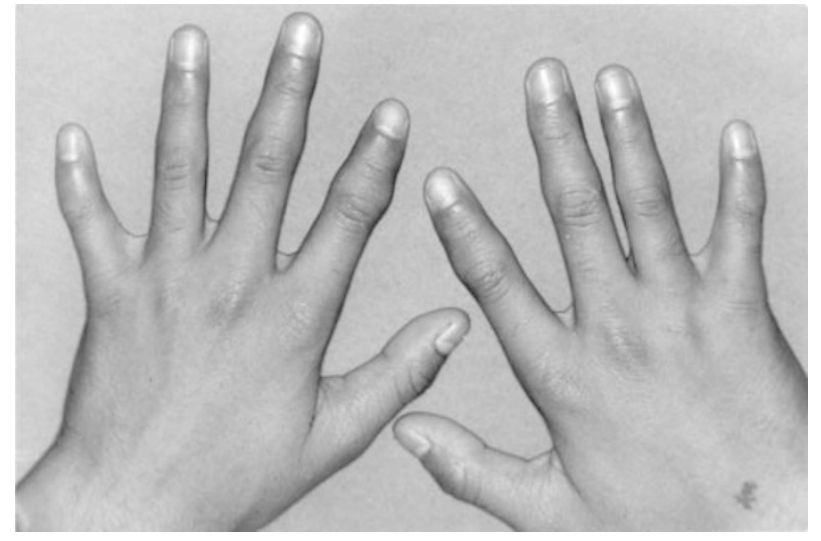

Figure 2 The hands of the oldest boy ( $\mathrm{V}-1$ in Figure 1). Note swelling of the middle phalanx of the second, third and fourth finger, and clinodactyly of the fifth finger.

a

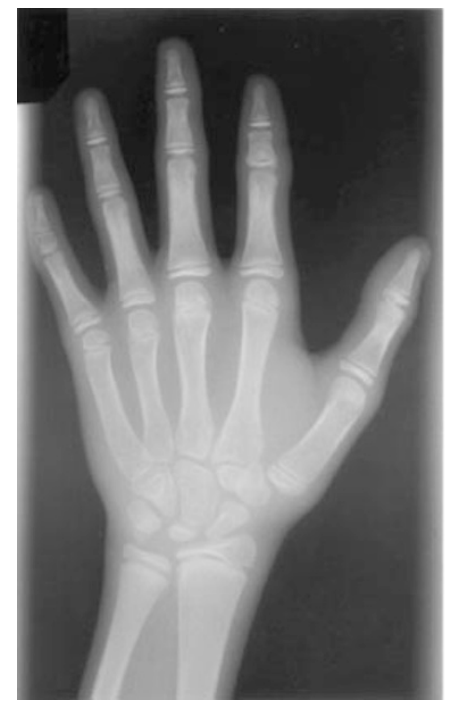

b

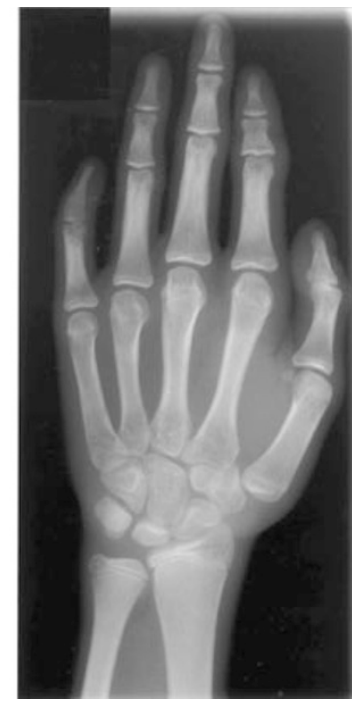

Figure 3 X-ray images of left hand of affected boy aged 16 (a) and 18 (b) years. The epiphyseal ossification centres were absent in the middle and distal phalanges of the fifth finger. Between age 16 and 18 years a synostosis of the distal interphalangeal joint of the fifth finger developed.

between the markers D18S78 and D18S866 (Figure 4). Genotypes of the chromosome 18 markers are shown in Table 2. The region of overlapping homozygosity in the affected children is delimited by proximal heterozygosity in V-1 (D18S78 and up) and distal heterozygosity in V-3 (D18S866 and down). The interval between D18S78 and D18S866 is approximately $30 \mathrm{cM}$ and corresponds to an inferred cytogenetic position on chromosome 18p11.31q11.2 (The Genetic Location Database [LDB], http://cedar. genetics.soton.ac.uk/public_html/ldb.html). Thus, the inter-

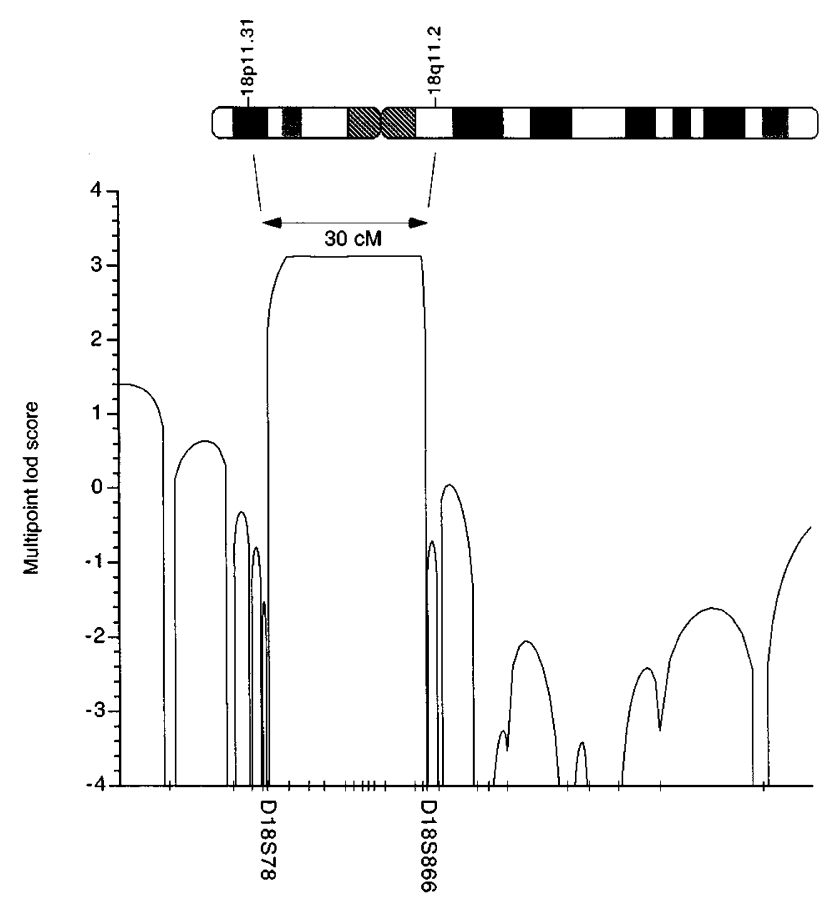

Figure 4 The graph illustrates MAPMAKER/HOMOZ linkage analysis of all (29) chromosome 18 markers tested. Marker positions are indicated on the $\mathrm{x}$-axis. The order and positions of the markers were taken from the Marshfield genetic map. The analysis mapped a locus for Seckel syndrome between D18S78 and D18S866, corresponding to the cytogenetic position illustrated on the ideogram at the top.

val spans the centromere and has a physical size of $\sim 20 \mathrm{Mb}$ (LDB) to $\sim 30 \mathrm{Mb}$ (The Unified Database [UDB], http:// bioinformatics.weizmann.ac.il/udb/).

The Seckel syndrome locus recently reported on 3q22.1q24 was excluded by a maximum multipoint lod score of -4.8 . Two regions on chromosome 6 and 7 showed maximum multipoint lod scores of 2.0, all other chromosomes showed maximum multipoint lod scores of $\leqslant 1.0$.

\section{Discussion}

The chromosome 18 locus reported here is the second locus for Seckel syndrome, thereby demonstrating genetic heterogeneity. The pronounced clinical heterogeneity is likely to mirror the genetic heterogeneity, and a number of distinct differences between the affected individuals in the chromosome 3 families $^{3}$ and the present family can be noticed. The mental and motor retardation in the present family is milder than in the chromosome 3 families where, eg, a 3-year-old girl had no words and was unable to sit without support. Likewise, the microcephaly of the proband of the first chromosome 3 family was more severe than in the present cases, and the growth retardation of the present cases is proportionate whilst in the chromosome 3 families the heads 
Table 2 Chromosome 18 marker genotypes of all family members analysed

\begin{tabular}{|c|c|c|c|c|c|c|c|c|c|c|c|c|c|c|}
\hline \multirow{3}{*}{$\frac{\text { Marker }^{a}}{\text { D18S59 }}$} & \multirow{2}{*}{\multicolumn{2}{|c|}{$\begin{array}{c}\text { Father } \\
I V-1\end{array}$}} & \multirow{2}{*}{\multicolumn{2}{|c|}{$\begin{array}{c}\text { Mother } \\
\text { IV-2 }\end{array}$}} & \multicolumn{9}{|c|}{ Children $^{b}$} & \\
\hline & & & & & & & & & & & & & & \\
\hline & 3 & 6 & 3 & 3 & 3 & 6 & 3 & 3 & 3 & 3 & 3 & 3 & 3 & \\
\hline D18S976 & 3 & 6 & 6 & 8 & 3 & 6 & 6 & 6 & 6 & 6 & 6 & 6 & 6 & 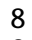 \\
\hline D18S1376 & 1 & 2 & 2 & 2 & 1 & 2 & 2 & 2 & 2 & 2 & 2 & 2 & 2 & \\
\hline D18S471 & 1 & 3 & 1 & 4 & 1 & 3 & 1 & 1 & 1 & 1 & 1 & 1 & 1 & . \\
\hline D18S452 & 6 & 6 & 6 & 8 & 6 & 6 & 6 & 6 & 6 & 6 & 6 & 6 & 6 & \\
\hline D18S967 & 2 & 4 & 2 & 2 & 2 & 4 & 2 & 2 & 2 & 2 & 2 & 2 & 2 & . \\
\hline D18S78 & 3 & 6 & 1 & 6 & 3 & 6 & 6 & 6 & 6 & 6 & 6 & 6 & 1 & \\
\hline D18S1163 & 1 & 8 & 1 & 1 & 1 & 1 & 1 & 1 & 1 & 1 & 1 & 1 & 2 & \\
\hline D18S843 & 1 & 2 & 2 & 3 & 2 & 2 & 2 & 2 & 2 & 2 & 2 & 2 & 2 & \\
\hline D18S464 & 1 & 1 & 1 & 1 & 1 & 1 & 1 & 1 & 1 & 1 & 1 & 1 & 1 & \\
\hline D18S1153 & 2 & 2 & 2 & 2 & 2 & 2 & 2 & 2 & 2 & 2 & 2 & 2 & 2 & . \\
\hline D18S1150 & 1 & 3 & 1 & 3 & 3 & 3 & 3 & 3 & 3 & 3 & 3 & 3 & 1 & 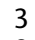 \\
\hline D18S1158 & 2 & 2 & 2 & 2 & 2 & 2 & 2 & 2 & 2 & 2 & 2 & 2 & 2 & . \\
\hline D18S542 & 4 & 6 & 4 & 6 & 4 & 4 & 4 & 4 & 4 & 4 & 4 & 4 & 4 & \\
\hline D18S53 & 6 & 8 & 6 & 8 & 6 & 6 & 6 & 6 & 6 & 6 & 6 & 6 & 6 & $\varepsilon$ \\
\hline D18S453 & 4 & 6 & 4 & 7 & 4 & 4 & 4 & 4 & 4 & 4 & 4 & 4 & 4 & 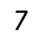 \\
\hline D18S869 & 2 & 4 & 1 & 2 & 2 & 2 & 2 & 2 & 2 & 2 & 2 & 2 & 1 & 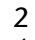 \\
\hline D18S1107 & 1 & 4 & 1 & 4 & 4 & 4 & 4 & 4 & 4 & 4 & 4 & 4 & 1 & 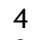 \\
\hline D18S480 & 1 & 1 & 1 & 3 & 1 & 1 & 1 & 1 & 1 & 1 & 1 & 1 & 1 & 3 \\
\hline D18S866 & 1 & 1 & 1 & 3 & 1 & 1 & 1 & 1 & 1 & 3 & 1 & 1 & 1 & 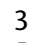 \\
\hline D18S877 & 4 & 5 & 4 & 5 & 4 & 4 & 4 & 4 & 4 & 5 & 4 & 4 & 4 & 5 \\
\hline D18S536 & 4 & 4 & 4 & 5 & 4 & 4 & 4 & 4 & 4 & 5 & 4 & 5 & 4 & 5 \\
\hline D18S535 & 4 & 7 & 5 & 7 & 5 & 7 & 5 & 7 & 7 & 7 & 7 & 7 & 7 & 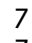 \\
\hline D18S970 & 6 & 7 & 6 & 6 & 6 & 7 & 6 & 7 & 6 & 7 & 6 & 7 & 6 & \\
\hline D18S858 & 2 & 6 & 5 & 6 & 6 & 6 & 6 & 6 & 2 & 5 & 5 & 6 & 6 & \\
\hline D18S64 & 3 & 3 & 3 & 8 & 3 & 3 & 3 & 8 & 3 & 3 & 3 & 8 & 3 & 8 \\
\hline D18S1147 & 2 & 2 & 2 & 3 & 2 & 3 & 2 & 2 & 2 & 3 & 2 & 2 & 2 & \\
\hline D18S857 & 3 & 3 & 2 & 2 & 2 & 3 & 2 & 3 & 2 & 3 & 2 & 3 & 2 & \\
\hline D18S871 & 3 & 3 & 3 & 4 & 3 & 3 & 3 & 4 & 3 & 4 & 3 & 4 & 3 & \\
\hline
\end{tabular}

${ }^{a}$ The order of markers is in accordance with the Marshfield genetic map. ${ }^{b}$ Regions of homozygosity in the four affected children are framed.

were small relative to other parameters. An interesting feature of all the affected siblings in the present study is the presence of small café au lait spots that, to our knowledge, has not been previously reported in Seckel syndrome. However, small patches of hyper- and hypo-pigmentation were described in a case with a Seckel-like syndrome. ${ }^{8}$ This case had also spindle-shaped fingers resembling the present cases, a feature not described in other Seckel syndrome cases. However, the child had increased spontaneous and induced chromosome breakage, developed pancytopenia at 16 months and died shortly after.

Although the 20-30 Mb wide candidate region identified spans the centromere, the non-centromeric region is still rather large and harbours a number of candidate genes for Seckel syndrome. One of these is the retinoblastoma-binding protein 8 (RBBP8) on $18 \mathrm{q} 11.2$. $^{9}$ It has been proposed that Seckel syndrome might be a disorder of DNA repair and replication, mainly based on the occurrence of increased spontaneous and induced chromosome breakage observed in a few cases with Seckel or Seckel-like syndrome. ${ }^{8,10,11}$ The oldest boy of the present study did not show increased spontaneous chromosome breakage. However, the presence of café au lait spots in the affected siblings indicates that the syndrome involves anomalies related to cellular dysplasia and that the underlying defect might involve, eg, DNA repair. A subset of the endogenous pool of RBBP8 polypeptides exists in a protein complex that includes both BRCA1 and BRCA1associated RING-domain protein (BARD1), and it has been suggested that RBBP8 can potentially modulate the functions ascribed to BRCA1 in DNA repair, transcriptional regulation, and/or cell cycle checkpoint control. ${ }^{12}$

Another interesting candidate gene in the region is $R A B 31$ encoding a small GTP-binding rab protein. ${ }^{13}$ Rab proteins represent a family of non-transforming proteins of the ras super-family that are involved in vesicular transport of molecules between cellular organelles. A number of families with X-linked mental retardation are caused by mutations in the GDI1 (rab GDP-dissociation inhibitor 1) gene, one of the genes involved in control of cycling between active and inactive state of the rab family. ${ }^{14}$ GDI1 is predominantly expressed in neural and sensory tissue, ${ }^{15}$ while the nearly ubiquitous pattern of $R A B 31$ expression $^{13}$ correlates well with the multiple organs affected in Seckel syndrome. However, the region co-segregating with Seckel syndrome in the present family is large and the work towards identification of the responsible disease gene would benefit from linkage analysis of additional families narrowing down the region and reducing the number of candidate genes. Genetic investigations of additional families would also be necessary for elucidation of possible further locus heterogeneity and molecular genetic delineation of this heterogeneous syndrome. 


\section{Acknowledgements}

The Danish Medical Research Council is thanked for financial support.

\section{References}

1 Seckel HPG: Bird-headed Dwarfs: Studies in Developmental Anthropology Including Human Proportions. Springfield, IL: Charles C Thomas, 1960

2 Majewski F, Goecke T: Studies of microcephalic primordial dwarfism I: approach to a delineation of the Seckel syndrome. Am J Med Genet 1982; 12: 7-21.

3 Goodship J, Gill H, Carter J, Jackson A, Splitt M, Wright M: Autozygosity mapping of a seckel syndrome locus to chromosome 3q22. 1- q24. Am J Hum Genet 2000; 67: 498-503.

4 Kjær I, Hansen N, Becktor KB, Birkebæk N, Balslev T: Craniofacial morphology, dentition and skeletal maturity in four siblings with Seckel syndrome. Cleft Palate, 2001; in press.

5 Broman KW, Murray JC, Sheffield VC, White RL, Weber JL: Comprehensive human genetic maps: individual and sexspecific variation in recombination. Am J Hum Genet 1998; 63: $861-869$.

6 Lathrop GM, Lalouel JM, Julier C, Ott J: Strategies for multilocus linkage analysis in humans. Proc Natl Acad Sci USA 1984; 81 $3443-3446$.

7 Kruglyak L, Daly MJ, Lander ES: Rapid multipoint linkage analysis of recessive traits in nuclear families, including homozygosity mapping. Am J Hum Genet 1995; 56: 519-527.
8 Woods CG, Leversha M, Rogers JG: Severe intrauterine growth retardation with increased mitomycin $C$ sensitivity: a further chromosome breakage syndrome. J Med Genet 1995; 32 :301305.

9 Fusco C, Reymond A, Zervos AS: Molecular cloning and characterization of a novel retinoblastoma-binding protein. Genomics 1998; 51: $351-358$.

10 Butler MG, Hall BD, Maclean RN, Lozzio CB: Do some patients with Seckel syndrome have hematological problems and/or chromosome breakage? Am J Med Genet 1987; 27: 645-649.

11 Esperou-Bourdeau H, Leblanc T, Schaison G, Gluckman E: Aplastic anemia associated with 'bird-headed' dwarfism (Seckel syndrome). Nouv Rev Fr Hematol 1993; 35: 99-100.

$12 \mathrm{Yu} \mathrm{X}$, Baer R: Nuclear localization and cell cycle-specific expression of CtIP, a protein that associates with the BRCA1 tumor suppressor. J Biol Chem 2000; 275: 18541-18549.

13 Chen D, Guo J, Miki T, Tachibana M, Gahl WA: Molecular cloning of two novel rab genes from human melanocytes. Gene 1996; 174: 129-134.

14 D'Adamo P, Menegon A, Lo Nigro C et al: Mutations in GDI1 are responsible for X-linked non-specific mental retardation. Nat Genet 1998; 19: 134-139.

15 Bachner D, Sedlacek Z, Korn B, Hameister H, Poustka A: Expression patterns of two human genes coding for different rab GDP-dissociation inhibitors (GDIs), extremely conserved proteins involved in cellular transport. Hum Mol Genet 1995; 4: $701-708$. 